\title{
Applying Intuitionistic Fuzzy Approach to Reduce Search Domain in an Accidental Case
}

\author{
Yasir Ahmad \\ Faculty of Computer Science \& \\ Information System \\ Jazan University \\ Jizan, Saudi Arabia \\ yasir.ahmad@rediffmail.com
}

\author{
Sadia Husain \\ Faculty of Computer Science \& \\ Information System \\ Jazan University \\ Jizan, Saudi Arabia \\ Husain.sadi@gmail.com
}

\author{
Afshar Alam \\ Dept. of Computer Science \& \\ Information Technology \\ Jamia Hamdard University \\ Hamdard Nagar, New Delhi, India \\ mailtoafshar@rediffmail.com
}

\begin{abstract}
In this paper we are using intuitionistic fuzzy approach to minimize search domain in an accidental case where the data collected for investigation is intuitionistic fuzzy in nature. To handle these types of imprecise information we use intuitionistic fuzzy tolerance relation and translate intuitionistic fuzzy query to reach to the conclusion. Here we present an example of vehicle hit and run case where the accused had fled the accident spot within seconds leaving no clue behind.
\end{abstract}

Keywords- fuzzy sets, Intuitionistic fuzzy relation, Intuitionistic fuzzy database, Intuitionistic fuzzy tolerance.

\section{INTRODUCTION}

A fuzzy database utilizes the fuzzy logic, where fuzzy relational schemas are used to represent imprecise data. But in some application fuzzy sets are found unsatisfactory in capturing the information that includes some hesitation degree. So to deal with such application Intuitionistic fuzzy sets are used. Intuitionistic fuzzy set theory (IFS) is a significant generalization of fuzzy set. It was introduced by Krassimir Atanassov [1-4] in year 1983. Intuitionistic fuzzy sets can be useful in situations when description of a problem by a (fuzzy) linguistic variable, given in terms of a membership function only, seems insufficient to give best result. For example, in decision making problems, particularly in the case of medical diagnosis, sales analysis, new product marketing, financial services, etc.[5-6] there is a fair chance of the existence of a non-null hesitation part at each moment of evaluation of an unknown object.

When the data become intuitionistic fuzzy in nature we need Intuitionistic Fuzzy Databases (IFDB) as the fuzzy database is not appropriate for handling intuitionistic fuzzy data. IFDB was introduced by Biswas, De. and Roy[7-12].

\section{BACKGROUND DETAILS}

Intuitionistic fuzzy set (IFS), developed by Atanassov is a powerful tool to deal with vagueness. A prominent characteristic of IFS is that it assigns to each element a membership degree and a non-membership degree, and thus, the IFS constitutes an extension of Zadeh's fuzzy set, which only assigns to each element a membership degree. Recently various applications of IFS to artificial intelligence have appeared - intuitionistic fuzzy expert systems, intuitionistic fuzzy neural networks, intuitionistic fuzzy decision making, intuitionistic fuzzy machine learning, intuitionistic fuzzy semantic representations.

The strength of relations as information models in knowledge based system derives from their fundamental ability to describe observed or predicted "connections", expressed as facts or rules, between selected objects of discourse. The use of fuzzy relations originated from the observation that real life objects can be related to each other to a certain degree (just like elements can belong to a fuzzy set to a certain degree); in this sense they are able to model vagueness. They are still intolerant of uncertainty, however, since there is no means of attributing reliability or confidence information to the membership degrees. Various frameworks have been developed to deal with this imperfection, amongst others. Here we will concentrate on the IF approach. A possible semantics for an IF relations taking inspiration from classical possibility theory was presented in [13-14]. Basically, the idea is to treat an IF relation as an elastic restriction that allows us to discriminate between the more or less plausible values for a variable.

For instance, a statement like "John is old" does not allow us to infer John's exact age, yet provides some support in favor of the older ages (allowing that those ages are, to a given extent, possible for him), as well as negative evidence against the younger ones (expressing some certainty or necessity that those ages can't in fact be his). We model this observation by indicating how much the original condition "John is old" needs to be stretched in order for John's age to assume this particular value: we assign two separate $[0,1]$ valued degrees $\mu_{\mathrm{A}}(\mathrm{u}) \& v_{\mathrm{A}}(\mathrm{u})$ to every age $\mathrm{u}$ in the considered domain, the first one indicating the possibility that the john's age assumes this particular value and the second one reflecting our certainty that differ from the given value $u$. In classical possibility theory symmetry between the two indexes is imposed, however, in a sense that from knowledge it is impossible that john is 25 year old $(\mu(25)=0)$, we immediately derive that it is completely certain that he is not 25 i.e. $v(25)=$ 1 ), and more generally from $\mu(u)=\alpha$ follows $v(u)=1-\alpha$. Taken together, the various degrees $\mu(\mathrm{u})$ give rise to a fuzzy 
set. But what if we cannot be sure that the observer is fully credible?

In other words, we can have varying degrees of trust in an observer, ranging from unconditional in confidence to full creditworthiness, and we should be able to model that trust accordingly; which can be done conveniently by letting the certainty degree $v(u)$ range between 0 and $1-\mu(u)$. This justifies the use of a more general intuitionistic fuzzy, rather than a fuzzy, relation as a model of describing observations.

\section{PRELIMINARY}

We present some basic preliminaries for the better understanding of our work.

\section{A. Intuitionistic fuzzy sets}

Let a set $\mathrm{E}$ be fixed. An IFS A in E is an object of the following form:

$\mathrm{A}=\left\{\left(\mathrm{x}, \mu_{\mathrm{A}}(\mathrm{x}), v_{\mathrm{A}}(\mathrm{x})\right) \mathrm{x} \in \mathrm{E}\right\}$,

When $v_{A}(x)=1-\mu_{A}(x)$ for all $x \in E$ is ordinary fuzzy set.

In addition, for each IFS $\mathrm{A}$ in $\mathrm{E}$, if

$\pi_{\mathrm{A}}(\mathrm{x})=1-\mu_{\mathrm{x}}-v_{\mathrm{x}}$

Then $\pi_{\mathrm{A}}(\mathrm{x})$ is called the degree of indeterminacy of $\mathrm{x}$ to $\mathrm{A}$, or called the degree of hesitancy of $\mathrm{x}$ to $\mathrm{A}$.

\section{B. Intuitionistic fuzzy relation}

Let $\mathrm{X}$ and $\mathrm{Y}$ are two sets. An Intuitionistic fuzzy relation (IFR) $\mathrm{R}$ [15-16] from $\mathrm{X}$ to $\mathrm{Y}$ is an IFS of $\mathrm{X} \times \mathrm{Y}$ characterized by the membership function $\mu_{R}$ and non-membership function $v_{R}$. An IFR $R$ from $X$ to $Y$ will be denoted by $R(X \rightarrow Y)$.

$\mathrm{R}=\left\{<(\mathrm{x}, \mathrm{y}), \mu_{\mathrm{R}}(\mathrm{x}, \mathrm{y}), v_{\mathrm{R}}(\mathrm{x}, \mathrm{y})>\mathrm{x} \in \mathrm{X}, \mathrm{y} \in \mathrm{Y}\right\}$

Where $\mu_{\mathrm{R}}: \mathrm{X} \times \mathrm{Y} \rightarrow[1,0]$ and $\nu_{\mathrm{R}}(\mathrm{x}): \mathrm{X} \times \mathrm{Y} \rightarrow[1,0]$ satisfies the condition

$0 \leq \mu_{\mathrm{R}}(\mathrm{x}, \mathrm{y})+v_{\mathrm{R}}(\mathrm{x}, \mathrm{y}) \leq 1$

For every $(\mathrm{x}, \mathrm{y}) \in \mathrm{X} \times \mathrm{Y}$

\section{Intuitionistic fuzzy Tolerance Relation}

An intuitionistic fuzzy relation $\mathbf{R}$ on the Cartesian product $(\mathrm{X} \times \mathrm{X})$, is called: An intuitionistic fuzzy tolerance relation if $\mathrm{R}$ is reflexive and symmetric.

\section{1) Reflexive}

An IF relation $\mathrm{R}(\mathrm{X} x \mathrm{Y})$ is said to be reflexive if

$$
\mathrm{x} 1, \mathrm{x} 2 \in \mathrm{X}, \mu \mathrm{R}(\mathrm{x}, \mathrm{x})=1
$$

2) Symmetric

An IF relation $\mathrm{R}(\mathrm{X} \times \mathrm{Y})$ is said to be symmetric if $\mathrm{x} 1, \mathrm{x} 2 \in \mathrm{X}$

$\mu \mathrm{R}(\mathrm{x} 1, \mathrm{x} 2)=\mu \mathrm{R}(\mathrm{x} 2, \mathrm{x} 1)$ and

$$
v_{R}(x 1, x 2)=v_{R}(x 2, x 1)
$$

\section{Intuitionistic Fuzzy Database}

As an intuitionistic fuzzy set is a generalization of fuzzy set, Buckles and Petry defined fuzzy database [17-21] as a generalization of classical database. There model is based on similarity relation for each domain of fuzzy database. A fuzzy relational database is defined as set of relations where each relation is a set of tuple. If $\mathrm{t}_{\mathrm{i}}$ represents the $\mathrm{i}_{-}{ }^{\text {th }}$ tuple it has form $\left(\mathrm{d}_{\mathrm{i} 1}, \mathrm{~d}_{\mathrm{i} 2}, \ldots \ldots . . \mathrm{d}_{\mathrm{im}}\right)$. In a classical relational database each component $\mathrm{d}_{\mathrm{ij}}$, of the tuple is an element of the corresponding scalar domain $D_{j}$ i.e. $d_{i j}$ belongs to $D_{j}$. But in case of fuzzy relational database, the element of the tuple consists of either singleton or crisp subset of the scalar domain.

\section{1) Definition 1}

An intuitionistic fuzzy database is a set of relation where each pair of such relation $\mathrm{R}$ is a subset of the cross product:

$$
2^{\mathrm{D} 1} \times 2^{\mathrm{D} 2} \times \ldots \ldots 2^{\mathrm{Dm}}
$$

Where $2^{\mathrm{Di}}=\mathrm{P}\left(\mathrm{D}_{\mathrm{i}}\right)-\phi$. and $\mathrm{P}\left(\mathrm{D}_{\mathrm{i}}\right)$ is the power set of $\mathrm{D}_{\mathrm{i}}$, here $\mathrm{R}$ is called the intuitionistic fuzzy database relation.

\section{2) Definition 2}

Let $\mathrm{R} \subseteq 2^{\mathrm{D} 1} \times 2^{\mathrm{D} 2} \times \ldots \ldots \ldots 2^{\mathrm{Dm}}$ be an intuitionistic fuzzy database relation. An intuitionistic fuzzy tuple (with respect to $\mathrm{R}$ ) is an element of $\mathrm{R}$.

Let $\mathrm{t}_{\mathrm{i}}=(\mathrm{di} 1, \mathrm{di} 2, \ldots, \mathrm{dim})$ be an intuitionistic fuzzy tuple. An interpretation of $t$, is a tuple $=\left(a_{1}, a_{2}, \ldots, a_{m}\right)$ where $a_{j} \in d_{i j}$ for each domain Dj.

For each domain $D_{j}$ if $T_{j}$ be an intuitionistic fuzzy tolerance relation then the membership function is given by:

$$
\mu_{\mathrm{Tj}}: \mathrm{D}_{\mathrm{j}} \times \mathrm{D}_{\mathrm{j}} \rightarrow[0,1]
$$

And the non membership function is given by

$$
v_{\mathrm{Tj}}: \mathrm{D}_{\mathrm{j}} \times \mathrm{D}_{\mathrm{j}} \rightarrow[0,1]
$$

Satisfying Atanassov's condition

\section{APPLICATION}

In this section we present an application or a case that utilizes the intuitionistic fuzzy concept specially intuitionstic fuzzy relation.

Suppose, on a highway an accident has taken place and the accident spot is $15 \mathrm{~km}$ away from a check post where the information of all the vehicles that are passed by is recorded on a CCTV camera. Within seconds car driver along with the car fled the spot. Now the source of identification about the accused vehicle is the information given by an eye witness and the record of the vehicles that passed by the check post.

The information given by an eye witness is that the accused vehicle is "more or less full size, somewhat grayish 
color, and somewhat similar to SUV type". Now the police match the provided information with the vehicles that passed by the check post within one hour of the accident took place and the resultant database is given by tables presented here.

TABLE I.

\begin{tabular}{|l|l|l|l|}
\hline $\begin{array}{c}\text { Vehicl } \\
\text { e No }\end{array}$ & $\begin{array}{c}\text { Vehicle } \\
\text { Type }\end{array}$ & \multicolumn{1}{|c|}{ Clor } & \multicolumn{1}{|c|}{ Build } \\
\hline UP-E09XY & SUV & $\begin{array}{l}\text { Silver } \\
\text { Grey }\end{array}$ & Mid-size \\
\hline UP-Y0991 & Sedan & Black & Micro \\
\hline MP-B6799 & SUV & $\begin{array}{l}\text { Pearl } \\
\text { Grey }\end{array}$ & Sub-compact \\
\hline AP-GH800 & Van & White & compact \\
\hline MP-B6789 & Van & Black & compact \\
\hline UP-GH688 & Jeep & $\begin{array}{l}\text { Silver } \\
\text { Grey }\end{array}$ & Full-size \\
\hline UK-T9654 & SUV & $\begin{array}{l}\text { Pearl } \\
\text { Grey }\end{array}$ & Sub-compact \\
\hline MP-B5468 & Sedan & White & Compact \\
\hline
\end{tabular}

Now we constitute the IF tolerance relation of the attributes included in above database to reduce our suspicion domain.

As we know that the eye witness usually has lots of imprecision in their information and we have to consider this fact also.

Example if an eyewitness says it was a midsize car with membership degree 0.08 and non degree 0.02 means that he is $80 \%$ sure that this is a midsize car and $20 \%$ not sure about it. As the $80 \%$ is considerably high figure so we assume that car is mid-size with no hesitation.

Now we ask about his understanding of an attribute like full-size and its similarity with others. According to him similarity between full size and midsize is with a degree of $(0.8,0.1)$ and hesitation as 0.1 .

Similarly the similarity between midsize and compact car is $(0.6,0.4)$ with no hesitation. We can finally make Intuitionistic fuzzy tolerance relations based on the description provided by him and his understanding about the attributes of the vehicles.

The domain of Vehicle - Type $=\{$ Jeep, SUV, Sedan, Van $\}$ The domain of color $=\{$ Pearl Grey, Silver Grey, Black, White $\}$ The domain of Build $=\{$ Full -size, Mid-size, Compact, subcompact, Micro\}

Consider the IF tolerance relation $T_{D 1}$ where $D_{1}=$ Vehicle Type of the Car, given by

TABLE II.

\begin{tabular}{|ll|l|l|l|l|}
\hline \multicolumn{1}{|c|}{ T } & Jeep & SUV & Sedan & Van \\
\hline
\end{tabular}

\begin{tabular}{|l|l|l|l|l|}
\hline Jeep & $(1,0)$ & $(0.8,0.1)$ & $(0.4,0.4)$ & $(0,1)$ \\
\hline UV $^{\mathbf{S}}$ & $(0.8,0.1)$ & $(1,0)$ & $(0.5,0.4)$ & $(0,0.9)$ \\
\hline dan $^{\text {Se }}$ & $(0.4,0.4)$ & $(0.5,0.4)$ & $(1,0)$ & $(0.4,0.4)$ \\
\hline an V & $(1,0)$ & $(0,0.9)$ & $(0.4,0.4)$ & $(1,0)$ \\
\hline
\end{tabular}

Consider the IF tolerance relation $\mathrm{T}_{\mathrm{D} 2}$ where $\mathrm{D}_{2}=$ color of the Car, given by

TABLE III.

\begin{tabular}{|c|l|l|l|l|}
\hline $\mathbf{T}_{\mathbf{D} 2}$ & \multicolumn{1}{|c|}{$\begin{array}{c}\text { Pearl } \\
\text { Grey }\end{array}$} & \multicolumn{1}{|c|}{ Silver } & \multicolumn{1}{|c|}{ Black } & \multicolumn{1}{|c|}{ White } \\
\hline $\begin{array}{c}\text { Pearl } \\
\text { Grey }\end{array}$ & $(1,0)$ & $(0.8,0.2)$ & $(0.2,0.7)$ & $(0,1)$ \\
\hline $\begin{array}{c}\text { Silve } \\
\text { r Grey }\end{array}$ & $(0.8,0.2)$ & $(1,0)$ & $(0.3,0.4)$ & $(0.5,0.2)$ \\
\hline Blac & $(0.2,0.7)$ & $(0.3,0.4)$ & $(0,1)$ & $(0.4,0.4)$ \\
\hline e Whit & $(0.1,0.7)$ & $(0.5,0.2)$ & $(0.4,0.4)$ & $(0,1)$ \\
\hline
\end{tabular}

Consider the IF tolerance relation $\mathrm{T}_{\mathrm{D} 3}$ where $\mathrm{D}_{3}=$ Build of the Car, given by

TABLE IV.

\begin{tabular}{|l|l|l|l|l|l|}
\hline \multicolumn{1}{|c|}{$\mathbf{T}_{\mathbf{D} 3}$} & \multicolumn{1}{|c|}{ Full- } & \multicolumn{1}{|c|}{ Mid } & \multicolumn{1}{|c|}{ Com } & $\begin{array}{c}\text { Sub- } \\
\text { size }\end{array}$ & \multicolumn{1}{|c|}{-size } \\
\hline Full-Size & $(1,0)$ & $(0.7,0.3)$ & $(0.5,0.4)$ & $(0.3,0.6)$ & $(0,1)$ \\
\hline $\begin{array}{c}\text { Mid } \\
\text {-Size }\end{array}$ & $(0.7,0.3)$ & $(1,0)$ & $(0.6,0.4)$ & $(0.4,0.5)$ & $(0,0.9)$ \\
\hline $\begin{array}{c}\text { com } \\
\text { pact }\end{array}$ & $(0.5,0.4)$ & $(0.6,0.4)$ & $(1,0)$ & $(0.6,0.3)$ & $(0.3,0.6)$ \\
\hline $\begin{array}{c}\text { Sub- } \\
\text { compact }\end{array}$ & $(0.3,0.6)$ & $(0.4,0.5)$ & $(0.6,0.3)$ & $(1,0)$ & $(0.8,0.2)$ \\
\hline ro Mic & $(0,1)$ & $(0.0 .9)$ & $(0.3,0.6)$ & $(0.8,0.2)$ & $(1.0)$ \\
\hline
\end{tabular}

Next target is to find the accused vehicle which is according to the eyewitness is "more or less full size, somewhat grayish color, and somewhat similar to SUV type". We can translate this intuitionistic fuzzy query into relational algebra form:

(Project (select (VEHICLE DATA)

where VEHICLE TYPE ='SUV',

COLOR='GREY',

BUILD='FULL-SIZE' 
with LEVEL (VEHICLE TYPE) $=.8$

$\operatorname{LEVEL}(\mathrm{COLOR})=.7$

LEVEL $($ BUILD) $=.8)$

with LEVEL $(\mathrm{NAME})=0.0$

LEVEL (VEHICLE TYPE) $=.8$

LEVEL $($ COLOR $)=.7$

LEVEL $($ BUILD) $=.8)$

giving LIKELY ACCUSED VEHICLE). relation.

Result: The above query giving rise to the following

TABLE V : Accused Vehicle

\begin{tabular}{|l|l|l|l|}
\hline No Vehicle & $\begin{array}{c}|c| \\
\text { Type }\end{array}$ & \multicolumn{1}{c|}{ color } & \multicolumn{1}{c|}{ Build } \\
\hline UP-E09XY & SUV & Silver Grey & Mid-size \\
\hline UP-GH688 & Jeep & Silver Grey & Full-size \\
\hline
\end{tabular}

So from the result based on eyewitness information and checkpoint data it is concluded that two vehicle (UP-E09XY, UP-GH688) should be put under surveillance.

\section{CONCLUSION}

This paper deals with the application of Intuitionistic fuzzy approach to find out ran away accuse of a car accident. Here we consider the information of an eye witness and constitute IF tolerance relation based on information provided.

It has been shown that how the use of IF tolerance relation and description about the vehicle which is finally translated into an IF query reduces the search domain.

\section{REFERENCES}

[1] Atanassov, K., "Intuitionistic fuzzy sets", Fuzzy sets and Systems, 20 (1986) 87-96.

[2] Atanassov, K.,"New operation defined over Intuitionistic fuzzy sets", Fuzzy sets and Systems, 61 (1994) 137-142.

[3] Atanassov, K, "More on Intuitionistic fuzzy sets", Fuzzy sets and Systems, 33 (1989) 37-46.
[4] Atanassov, K, "Remark on Intuitionistic fuzzy sets-III", Fuzzy sets and Systems (1995) 401-402.

[5] Szmidt, E. and Kacprzyk, J., "Group decision making under Intuitionistic fuzzy preference relations", Proceedings of the 7th IPMU Conf., Paris, (1998) 172-178.

[6] Szmidt, E. and Kacprzyk, J., "Decision making in an intuitionistic fuzzy environment", Proceedings of the Joint 4th EUROFUSE and 2nd SIC Conf., Budapest, (1999) 292-297.

[7] De, S.K., Biswas, R. and Roy, A.R., "On Intuitionistic fuzzy Databases, Proceedings of the second International Conference on IFS", Sofia, 3-4 October(1998) NIFS (4) 34-356.

[8] De, S.K., Biswas, R. and Roy, A.R., "An application of intuitionistic fuzzy sets in medical diagnosis", Fuzzy Sets and Systems 117 (2001) 209-213.

[9] De, S.K., Biswas, R. and Roy, A.R., "On Intuitionistic fuzzy sets", NIFS 3(4)(1997) 14-20.

[10] De, S.K, Biswas, R. and Roy, A.R., "Multicriteria based decision making using Intuitionistic fuzzy set theory", Journal of Fuzzy Math, 6(4)(1998)837-842.

[11] Alam, M.A., Sharfuddin, A. and Biswas, R., "On Intuitionistic Fuzzy Database", Proceedings of the 6 Joint Conference on Information Sciences, North Carolina(USA), March 8-13(2002) 92-96.

[12] Alam, M.A., Sharfuddin, A. and Biswas, R. , "Normalization of Intuitionistic Fuzzy Relational Databases", Proceedings of the seventh International Conference on IFS, Sofia, 23-24 October(2003) NIFS 19 (2003) 77-82.

[13] C. Cornelis, E.E. Kerre "Reliability of Information: Motivation for an Intuitionistic Theory of Possibility" Submitted to Fuzzy Sets and Systems.

[14] P. Burillo, H. Bustince, "Intuitionistic fuzzy relations (Part I)", Mathware Soft Comput. 2 (1995) 5-38.

[15] Burillo, P. and Bustince, H., "Intuitionistic fuzzy relations (Part I)", Mathware Soft Computing. 2 (1995) 5-38.

[16] Bustince, H. and Burillo, P., "Structures on intuitionistic fuzzy relations", Fuzzy Sets and Systems, 78 (1996) 293-303.

[17] Buckles, B. P. and Petry, F. E.,"A fuzzy representation of data for relational Databases," Fuzzy Sets \& Systems, 7(3) (1982) 213-226.

[18] Buckles, B. P. and Petry, F. E. , "Fuzzy Databases and their application", Fuzzy Information and Decision Processes, (1982) 361-371.

[19] Prade, H. and Testemale C, "Generalizing database relational algebra for the treatment of incomplete/uncertain information and vague queries." , in Proceedings qf2nd NAFIPS Workshop, Schenectady, NY 1983, Information Science, Vol 34, pp. 1 15-143 (1984).

[20] Baldwin J. F. and Zhou, S. Q, "A fuzzy relational inference language" Fuzzy Sets \& Systems, Vol. 14, pp. 155-174 (1984)

[21] Chen, G. Q. , "A step towards the theory of fuzzy relational database design", In Proceedings qf/FSA'91 World Congress, pp. 44-47, Brussels (1991). 